\title{
Family planning through the lens of men: Readiness, preferences, and challenges
}

\author{
Iram Kamran \\ Population Council \\ Zeba Tasneem \\ Population Council \\ Tahira Parveen \\ Population Council \\ Rehan M. Niazi \\ Population Council
}

Follow this and additional works at: https://knowledgecommons.popcouncil.org/departments_sbsr-rh

Part of the Demography, Population, and Ecology Commons, Family, Life Course, and Society Commons, and the International Public Health Commons How does access to this work benefit you? Let us know!

\section{Recommended Citation}

Kamran, Iram, Zeba Tasneem, Tahira Parveen, and Rehan M. Niazi. 2015. "Family planning through the lens of men: Readiness, preferences, and challenges." Washington, DC: Population Council, The Evidence Project. 


\section{Family Planning through the Lens of Men:}

$\frac{1}{4}$
$\frac{1}{0}$
$\frac{1}{0}$
$\frac{1}{0}$
0

\author{
Iram Kamran \\ Zeba Tasneem \\ Tahira Parveen \\ Rehan Niazi
}

August 2015

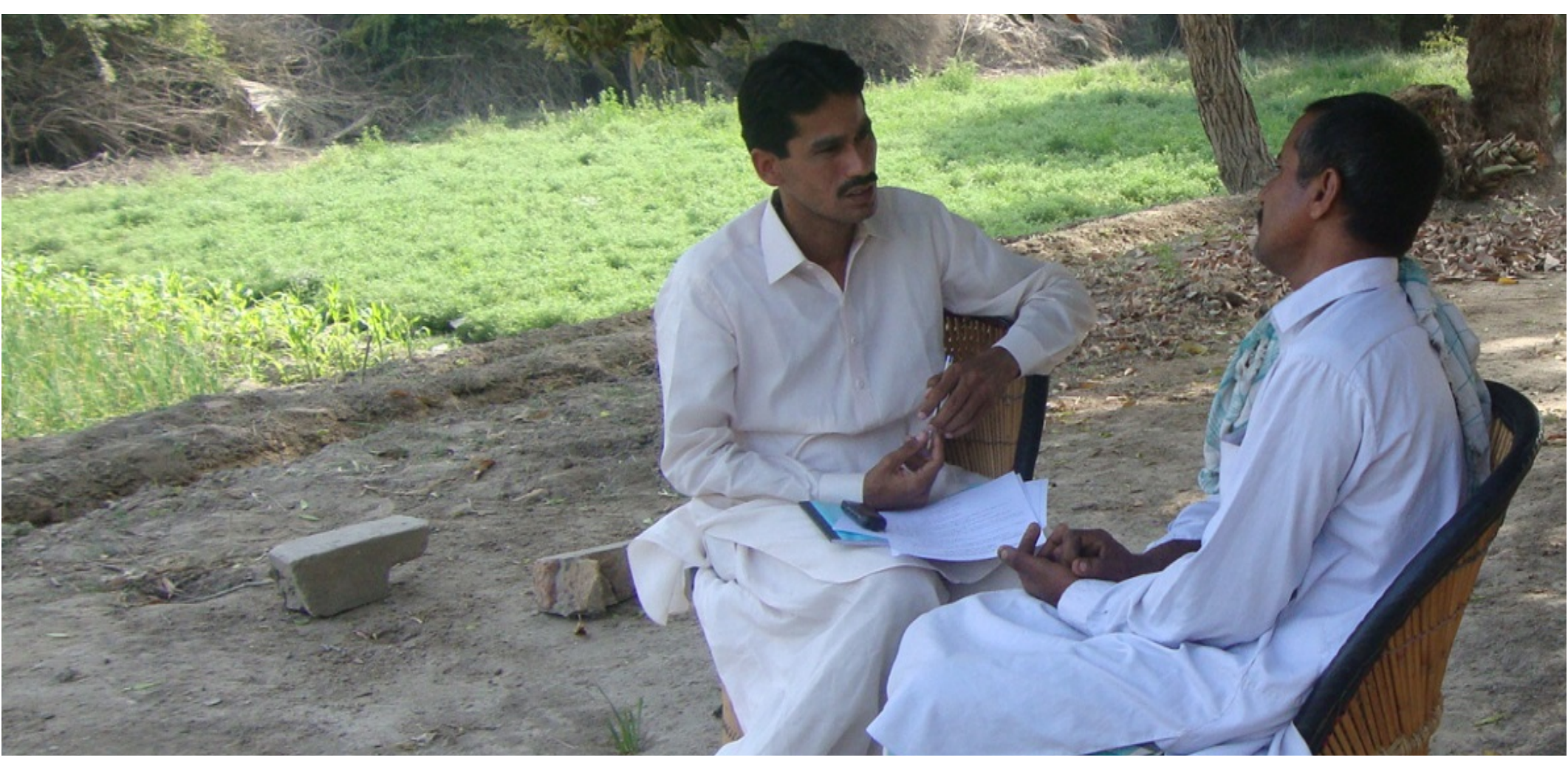





\section{Family Planning Through the Lens of Men: Readiness, Preferences, and Challenges}

Iram Kamran, Senior Program Officer, Population Council

Zeba Tasneem, Senior Program Officer, Population Council

Tahira Parveen, Program Officer, Population Council

Rehan Niazi, Deputy Program Officer, Population Council

August 2015 
The Evidence Project

Population Council

4301 Connecticut Ave. NW, Suite 280

Washington, DC 20008 USA

tel +12022379400

evidneceproject.popcouncil.org

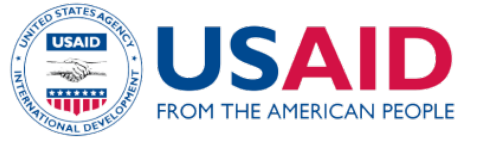

The Evidence Project is made possible by the generous support of the American people through the United States Agency for International Development (USAID) under the terms of cooperative agreement no. AID-

OAA-A-13-00087. The contents of this document are the sole responsibility of the Evidence Project and Population Council and do not necessarily reflect the views of USAID or the United States Government.

\section{[ The Evidence Project uses implementation science-the strategic Evidence generation, translation, and use of evidence-to strengthen and scale up family planning and reproductive health programs to reduce unintended pregnancies worldwide. The Evidence Project is led by the Population Council in partnership with INDEPTH Network, International Planned Parenthood Federation, Management Sciences for Health, PATH, Population Reference Bureau, and a University Research Network.}

Published in August 2015.

Suggested citation: Kamran, Iram, Zeba Tasneem, Tahira Parveen, and Rehan Niazi. 2015. "Family Planning through the Lens of Men: Readiness, Preferenes, and Challenges," Policy Paper. Washington, DC: Population Council, The Evidence Project.

(C) 2015 The Population Council, Inc. 


\section{Table of Contents}

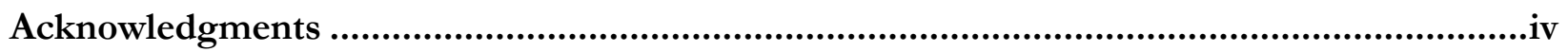

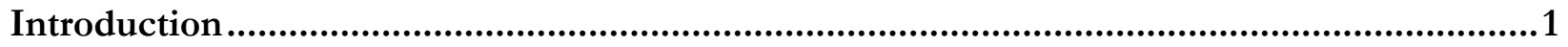

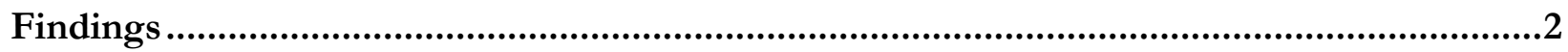

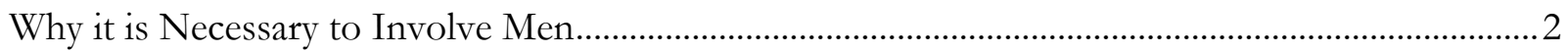

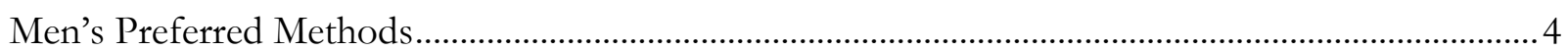

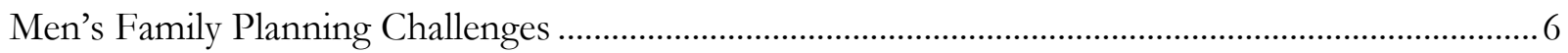

Supporting Men: The Potential of Male Providers in the Private Sector ...........................................14

Recommendations ..................................................................................................... 17

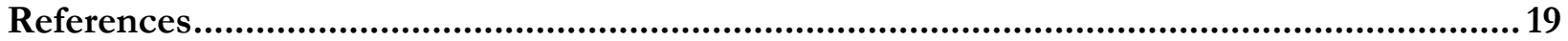

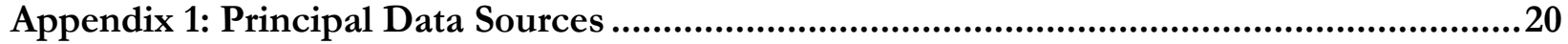




\section{Acknowledgments}

The authors would like to extend profound gratitude to Dr. Zeba Sathar, Country Director, Population Council, Pakistan, for her thoughtful and consistent review and guidance throughout the development of this policy paper.

We express our special thanks to Mrs. Seemin Ashfaq, Deputy Director Programs, for her motivation and continuous support in the preparation of this brief. We are also highly grateful to Dr. Gul Rashida, Consultant, for her technical review and valuable comments. We acknowledge and thank Mr. Maqsood Saddiq, Senior Program Officer, for his analysis.

We are grateful to Dr. Karen Hardee, Senior Associate and Director of the Evidence Project, and to Ms.

Ellen Weiss, Senior Communication Specialist of the Evidence Project, for their technical review and valuable comments.

We extend our sincere gratitude to Ms. Kiren Khan for her sound and timely editing. A special thanks is also due to Ms. Anneka Van Scoyoc for formatting this policy paper. 


\title{
Introduction
}

\begin{abstract}
AFTER DECADES OF WITNESSING THE COUNTRY STRUGGLE TO BRING ITS BURGEONING POPULATION FIGURES UNDER CONTROL, WITH MIXED SUCCESS, THERE ARE INDICATIONS THAT THE PENNY IS FINALLY DROPPING. MEN APPEAR TO BE RECOGNIZING THAT FAMILY PLANNING IS AS MUCH THEIR CONCERN AS THAT OF THEIR WIVES.
\end{abstract}

\author{
DAWN, Editorial, April 24, 2014
}

Family planning (FP) is urgently needed in Pakistan but progress remains slow. In its 2002 Population Policy, the country pledged to reduce its total fertility rate to 2.2 by 2020; at the London Summit in 2012, it further committed to increase the contraceptive prevalence rate (CPR) to 55 percent by the same year. Despite some important achievements, Pakistan's current CPR is only 35 percent, the total fertility rate is 3.8, and an alarming 20 percent of married couples of reproductive age express an unmet need for FP (NIPS and Measure DHS 2013).

Thus far, FP programming in the country has largely been directed at women, their husbands regarded, at best, as interested bystanders, and at worst, as grudging gatekeeepers impeding women's use of contraception. This has been mainly due to men's own perceptions of FP as women's business and their culturally-driven unease with the idea of family planning. However, recent research indicates that men's attitudes toward FP are changing and they are eager to be involved.

In several of its recent studies, the Population Council has focused on men's perspectives of FP in order to support an evidence-based agenda that brings men into mainstream FP programming. This paper synthesizes the data from these studies, as well as from other research, ${ }^{1}$ on Pakistani men's readiness to be more involved in FP, the challenges they face in FP adoption and continuation, and the preparedness of the health sector to respond to their needs.

\footnotetext{
${ }^{1}$ All citations are listed in the References section. The principal data sources used in this policy paper are described more fully in
} 


\section{Findings}

\section{WHY IT IS NECESSARY TO INVOLVE MEN}

Contraceptive use involves two equal stakeholders - the man and the woman — and logically both need to be addressed by FP interventions. Men's participation and sharing of responsibility in the practice of FP was recommended over two decades ago at the 1994 International Conference on Population and Development (ICPD). Yet, in Pakistan, men are largely excluded, both from interventions aimed at increasing contraceptive prevalence and from surveys and studies of contraceptive use dynamics (Kamran et al. 2013). As a result of this bias, men's views of FP have largely been ignored. This nearly exclusive focus on women has been cited as a main reason for the slow progress of FP in Pakistan (Avan and Akhund 2006).

Men want to be involved in family planning. As recently as a decade ago, available studies indicated that men did not give much thought to reproductive health concerns. For example, husbands in a village of Punjab were found to be largely unconcerned about FP. It was unheard of for couples to discuss fertility at the start of their reproductive lives, and husbands did not initiate any conversation on the subject. Due to lack of communication, spouses were unaware of each other's fertility intentions and desires (Arif et al. 2007). This general attitude may have made men relatively unapproachable for FP interventions. Currently, however, 72 percent of rural men and 86 percent of urban men disagree with the statement: "Family planning is women's business (NIPS and Measure DHS 2013)."

Men exert a powerful influence on women's use of contraception. Pakistan is a patriarchal society and men have a strong influence on family decisionmaking processes (Tuloro et al. 2006). Although men have not been the main subject of research related to FP in Pakistan, multiple studies have confirmed that their acquiescence is one of the most powerful influences in women's decision to adopt FP, in both rural and urban areas (Mahmood et al. 1996; Mahmood et al. 1997, Kiani 2003; Casterline et al. 2001; Ali 1999; Arif et al. 2007; Kamran et al. 2013; Kamran et al. 2015).

Men's own use of contraception now equals that of women. Not only are men important as enablers of FP use by women, they have also become significant contraceptive users in their own right. The latest Pakistan Demographic and Health Survey (2012-13) — one of the very few studies to explore men's FP intentions and behaviors - has revealed that male methods of contraception, specifically condoms and withdrawal, now account for 50 percent of contraceptive prevalence in the country. Efforts to increase contraceptive prevalence in Pakistan therefore need to focus as much on men's needs and challenges as women's.

Men's willingness to be involved has important implications for FP programming. Now that men are interested in and users of FP, addressing them as principal stakeholders (Tuloro et al. 2006) offers a promising avenue for fulfilling Pakistan's unmet need for FP and accelerating the CPR toward meeting FP2020 goals.

\section{UNDERSTANDING MEN'S READINESS FOR FAMILY PLANNING}

More men want planned births and are discussing this concern with their wives. FP intentions and behavior originate from fertility preferences: they indicate the desire of women and men to delay or limit the births of their children. Until recently, there was a considerable mismatch between the fertility preferences of 
men and women in Pakistan (Arif et al. 2007). However, surveys show an increasing convergence in responses of husbands and wives concerning family size (Figure 1). The proportion of couples who agree on family size has increased from 44 percent in 1990-91 to 58 percent in 2012-13 and the share of those who do not communicate about FP has shrunk from 36 percent to 11 percent, indicating progress in spousal communication on FP.

\section{FIGURE 1}

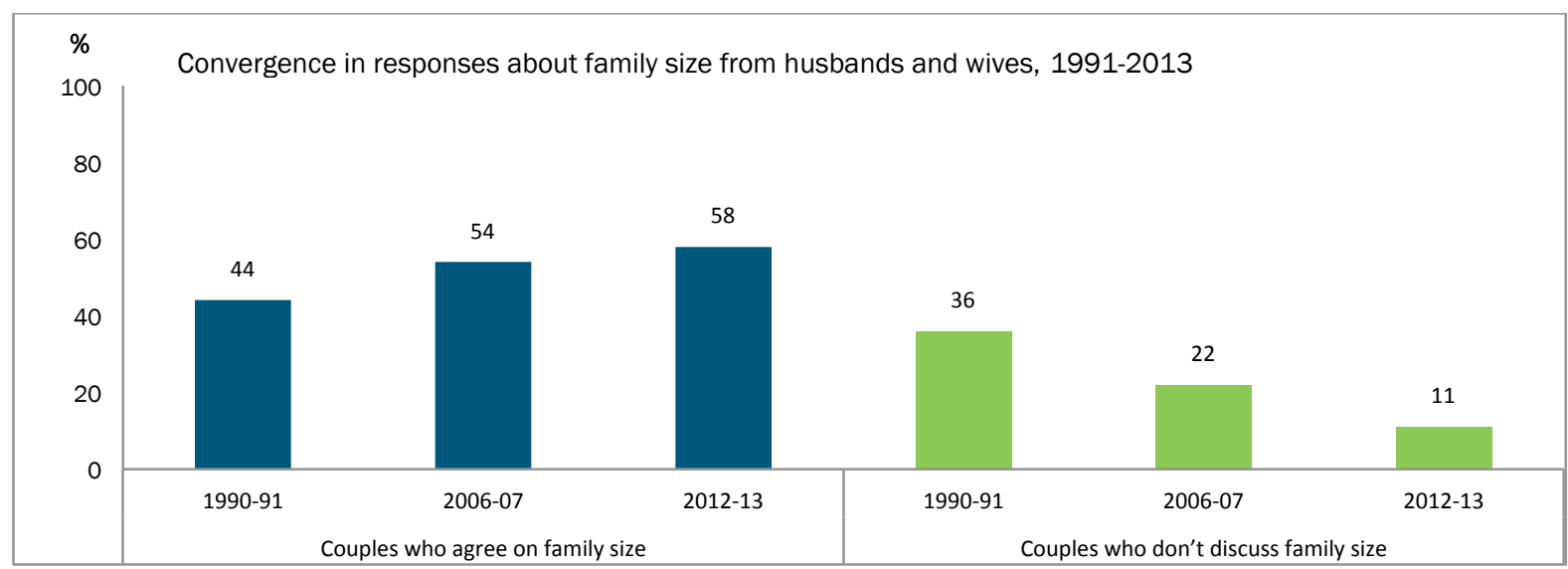

Source: Pakistan Demographic and Health Surveys 1990-91, 2006-07 and 2012-13

Financial pressure is the key reason for men's desire to plan births. The financial challenge of raising large families emerged as the key factor underlying the change in men's fertility preferences in a Punjab study (Kamran et al. 2013). This was confirmed by a national qualitative study in which men cited economic hardship and increasing inflation, as well as the desire to ensure proper upbringing and education of children as reasons for their interest in practicing FP. Men also voiced concern for their wife's health (Kamran et al. 2015).

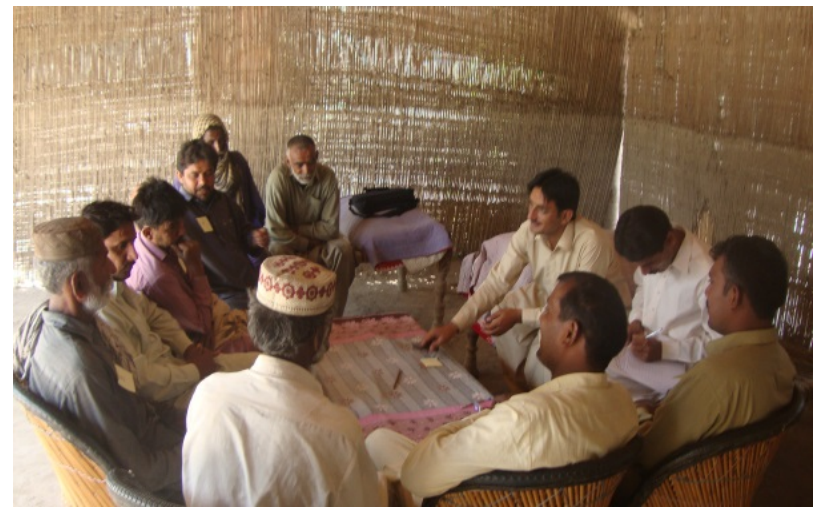

"Men are concerned that their means are limited and bow can they manage to provide their children with food, shelter and education."

- Male, rural area, Rahim Yar Khan

"In my opinion, planning is important. Family planning doesn't mean that you stop kids, or decide not to have them. Your problems, time, the mother's bealth, the father's bealth, bousebold conditions... all these things count. For this, planning is necessary."

- Male urban area, Pishin

"Actually people want to bring up their children nicely with education, and they can't look after many children this way, so they want 2 or 3 children so that they can give them full attention and that's why they do birth spacing. [To make sure they have enough means] For the clothes and shoes of the children [etc.], they want proper birth spacing between children."

- Male, urban area, Mardan 
Men recognize that FP is necessary to space births. In all four major provinces and in both urban and rural communities, more men now realize that either they or their wives should use a contraceptive method (Kamran et al. 2015). It has become less of a struggle for women to convince their husbands to practice FP (NIPS and Measure DHS 2013).

"Two days after we got married, we had a discussion about baving children. We decided not to rush into it and to wait a year. She started taking pills three days after our marriage for a gap of nine months."

- Male, rural area, Bahawalpur

"Yes, we used family planning at the start of our marital life. I wanted to have two years' space, which my wife wasn't agreeing to, but then I convinced ber and she agreed."

- Male, urban area, UmerKot

Men are more interested in spacing than in limiting births. While their FP preferences are catching up with those of women, there is more similarity in the desire for spacing births than in the desire to limit them (Figure 2). Looking at the preferences by parity, Figure 3 shows that there is only a slight difference between women and men in the desire for spacing up to 2-3 children. However, women remain far ahead of men in the desire to limit childbearing at the parity of 4-5 children and higher.

\section{FIGURE 2}

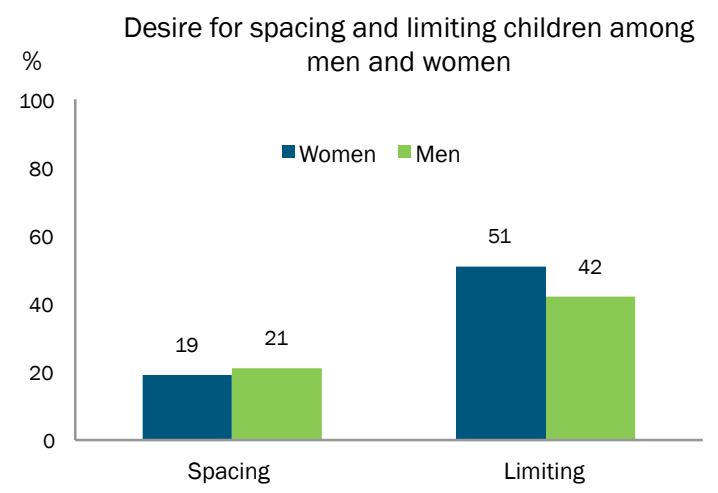

Source: Pakistan Demographic and Health Survey 2012-13

\section{FIGURE 3}

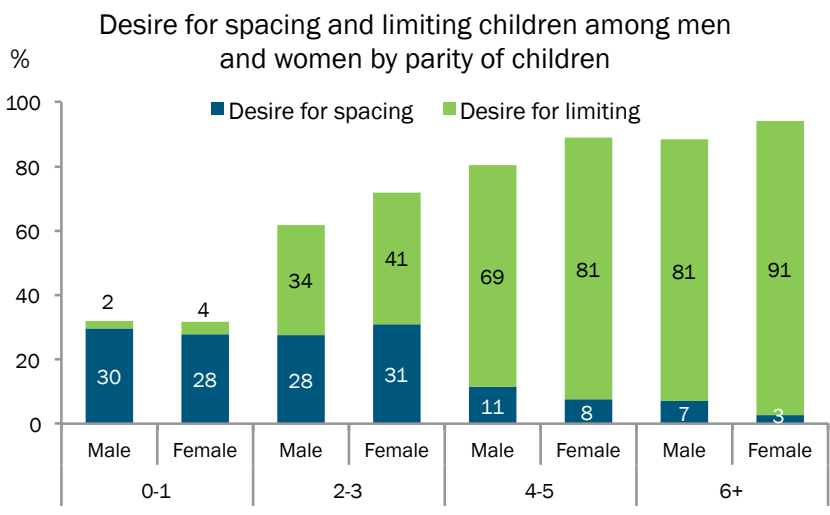

\section{MEN'S PREFERRED METHODS}

In general, men prefer to use modern contraceptive methods because they are reliable. Recent research shows that men recognize traditional methods' higher risk of failure and therefore, prefer that both men and women use modern methods of contraception (Kamran et al. 2015). ${ }^{2}$ This willingness to break from tradition shows a strong commitment to effective birth control.

\footnotetext{
2 The FP methods used in Pakistan may be categorized as traditional and modern methods, and as female and male methods. The commonly used modern female methods are oral contraceptive pills, injectable contraceptives, intrauterine contraceptive devices (IUCDs), and tubal ligation; traditional female methods consist of lactation amenorrhea (breastfeeding) and the rhythm (safe period) method. The three male methods are condoms, vasectomy, and the traditional method of withdrawal.
} 


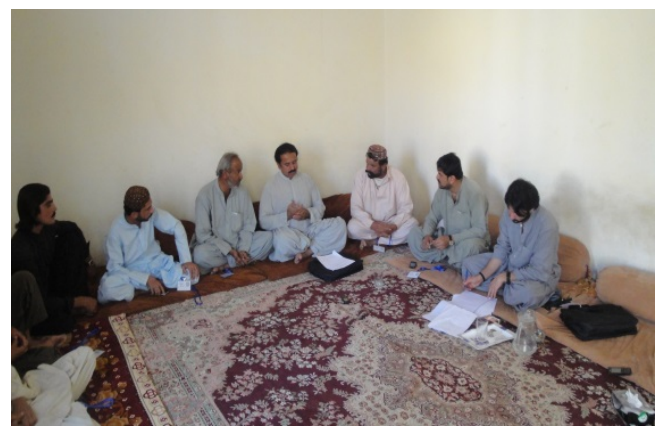

"Modern methods like condoms, injections, pills, and operation, are scientific methods; they have passed the inspection of every kind of doctor or different laboratories. That is why people are very satisfied by modern methods."

- Male, rural area, Mardan

"Traditional methods are not that safe; there is a chance of pregnancy in using them. Modern methods are safer."

- Male, semi urban area, Mansehra

Men's greater receptivity to FP has led to an increase in the use of male contraceptive methods. Figure 4 compares use of female and male FP methods in 1991 and in 2012-13 as reported by women. As the graph shows, the proportion of male methods in overall contraceptive use has risen markedly from 33 percent to 50 percent, while the share of female methods has declined. This trend indicates men's strong intest in and readiness to adopt FP.

\section{FIGURE 4}

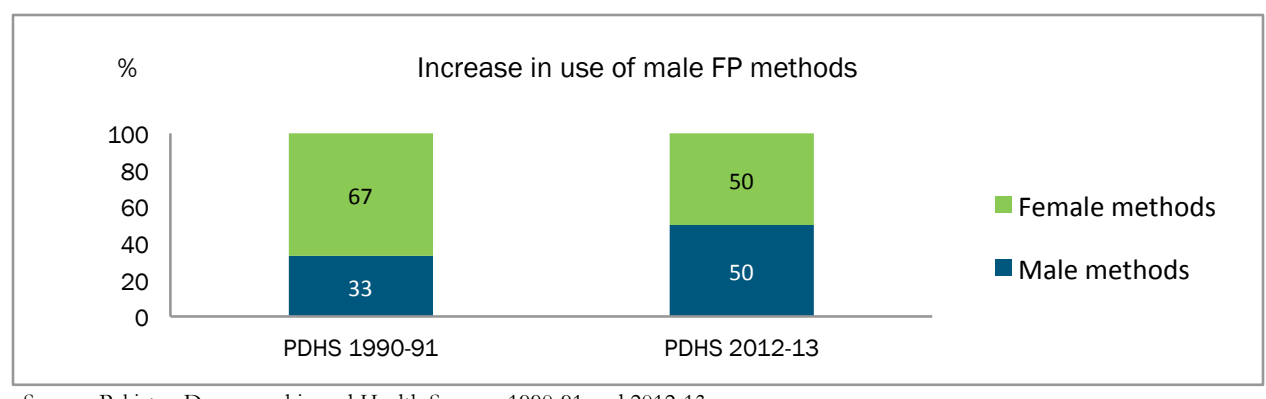

Source: Pakistan Demographic and Health Surveys 1990-91 and 2012-13

Most men prefer condoms to all other modern male as well as female contraceptive methods. It is surprising that the vast majority of men prefer condoms even to female methods of contraception. This preference holds across all provinces, including the more conservative Khyber Pakhtunkhwa (KP) and Balochistan (Kamran et al. 2015). PDHS 2012-13 also found that the increase in prevalence of modern contraceptives in Pakistan has mainly been driven by use of condoms.

Kamran et al. (2015) investigated the reasons for this preference and found that men perceive condoms to be cheap, easily available, and easy to use. Furthermore, they can be used with relative privacy (without the involvement of a health service provider), and are generally perceived to have no side effects. In areas served by the Lady Health Worker (LHW) Program, the presence of LHWs (community-based health workers) who can provide condoms to women at their doorsteps is an added convenience. It is possible that the increased preference for condoms also represents a rejection of female methods (due to difficulties in access or perceived side effects), but there is currently no evidence to confirm this.

"I like the condom. Its advantage is that it does not have any side effects and can be used for a longer period of time. This is why I like it."

-Male, rural area, Mansehra

"According to the advice of doctors, medical personnel and neighbors, condoms are fine. One doesn't need a prescription or have to go anywhere or suffer any disadvantage. You can get them from anywhere."

- Male, rural area, Khanewal 
Use of the less reliable method of withdrawal is increasing. While condoms are the most widely preferred male contraceptive method, successive PDHSs have found that growth in the prevalence of this method is slowing down. On the other hand, the prevalence of withdrawal — which is recognized by men to be less reliable_-is accelerating (Figure 5). In 1990-91, condoms were used by 3 percent of women's husbands, while withdrawal was used by only 1 percent. Currently, however, the two methods are used by roughly the same proportion of users (9 percent). The trend since 2006-07 is especially worrying: withdrawal has increased by 5 percentage points while condom use has grown by only 2 percentage points. Interestingly, according to PDHS 2012-13, withdrawal is used primarily by urban and educated men, who may be expected to be more aware of the high risk of method failure and have access to more reliable FP methods.

\section{FIGURE 5}

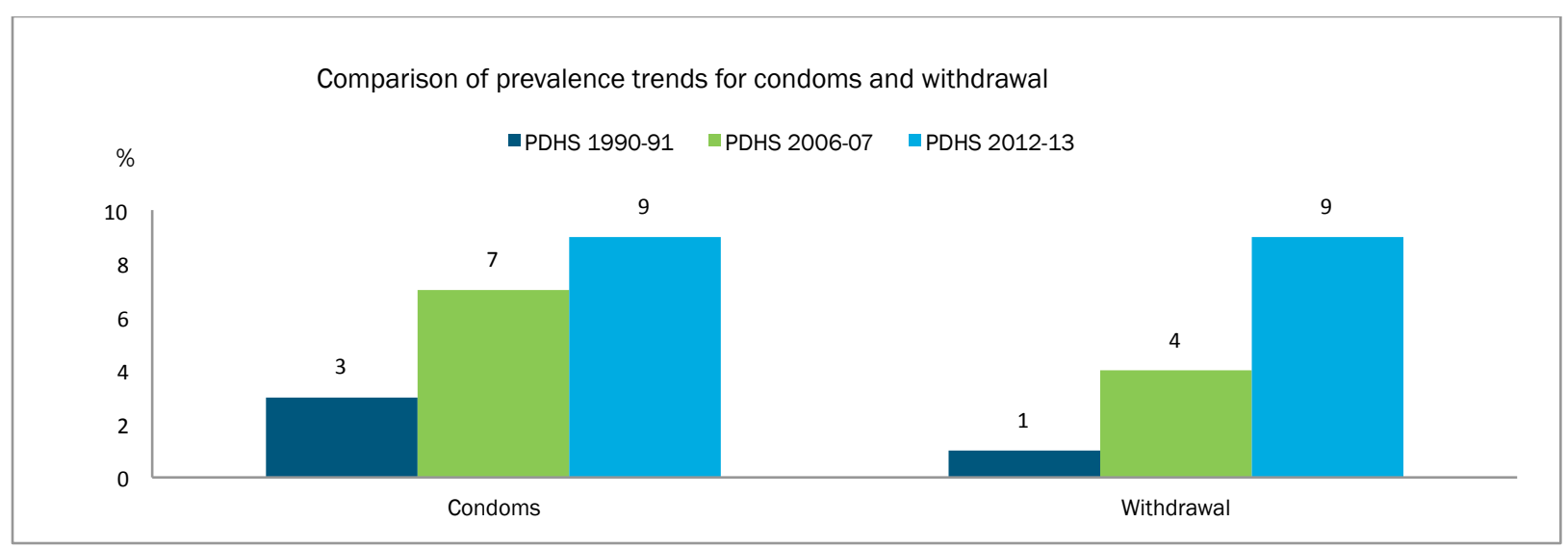

Source: Pakistan Demographic and Health Surveys 1990-91, 2006-07 and 2012-13

Increased use of withdrawal may be due to dissatisfaction with modern methods. The increasing use of withdrawal is troubling because the method is less dependable. It is also puzzling that this trend should arise among urban, educated men at a time when men in rural areas are showing a clear preference for modern contraceptive methods.

While there are no recent studies to explain this trend, past research may shed some light on the issue. A study conducted in 1998 found that the overriding reason for couples' preference for withdrawal to modern methods was concern about the possible adverse health effects of using modern alternatives (Population Council and Ministry of Population Welfare 1998). Couples' dissatisfaction with modern methods sometimes stemmed from actual experience of problems in contraceptive use but was more commonly based on perceptions of side effects that were derived from hearsay and often exaggerated. At the same time, they were less aware of the high risks of method failure. Although the availability, convenience, and privacy of withdrawal were regarded as important attributes, these were considered additional benefits rather than the primary reason for preferring this traditional method.

\section{MEN'S FAMILY PLANNING CHALLENGES}

The increased readiness of men to be involved in FP is very good news. However, the persistently slow increase in CPR and the rising use of the less reliable method of withdrawal, despite men's general commitment to planned families, indicate that this readiness is not translating into practice. This section outlines the key obstacles studies have identified in men's access to FP care. The first part outlines the general 
problems men experience in procuring FP care for themselves and for their wives. The second part focuses in greater detail on the problems men experience as users of male FP methods.

\section{Men Don't Know Enough About Specific Contraceptive Methods to Make an Informed Choice}

Lack of information about the full range of male and female FP methods is a key impediment for men residing in remote and rural communities in all provinces. Although many of these men want to practice FP, their lack of knowledge about usage, sources, and relative advantages and disadvantages reduces their ability to make an informed choice. This lack of knowledge is attributed by men to an absence of FP services, especially by male providers, and illiteracy (Kamran et al. 2015).

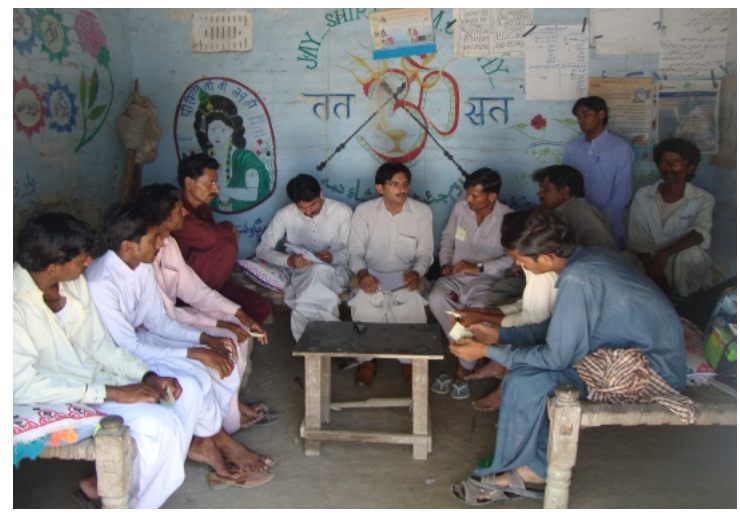

"This is a village. People bere don't know much. It's not a city where people know everything. These villagers are illiterate and they have very little information and don't bave any other reason (for not using FP)."

- Male, rural area, Khairpur

"We are villagers; we don't know anything-what is new, what it is used for. If we were to step out of the village, then we would know. If someone were to tell us, then we would know, (but) no one tells us. We are not educated: if someone tells us the wrong thing, then what can we do?"

- Male, rural area, Sibi

\section{Men Fear that Modern Contraceptives will have Side Effects}

Lack of information leads to and perpetuates another problem-apprehension regarding the use of FP methods. Fear of side effects, which may be experienced or simply be perceived to be related to contraceptive use, discourages men from using and allowing their wives to use contraception. In particular, men are apprehensive about the use of the IUCD and injectable contraceptives. Absence of proper knowledge about methods enhances and exaggerates the fear of side effects (Kamran et al. 2015).

"Women also use the copper-T but it has only side effects and no benefit. It causes wounds in the uterus and obesity and this further causes many diseases."

- Male, semi urban area, Mardan

\section{Men in Some Communities Feel Pressured to Have Many Children}

Although socio-cultural and religious resistance to the practice of FP has declined in the country, pressure to maximize progeny, especially sons, persists in many communities especially in Balochistan. Their reasons for not using FP are rooted more in their own traditions, where intergenerational tribal feuds claim the lives of many young adult sons, and so they desire to have more (Kamran et al. 2015). The social pressure to father many children, especially sons, and the disapproval of FP by local clerics and elders can prevent men from acting on their preference for fewer or more spaced births. Moreover, even though religious leaders have shown willingness to endorse birth spacing interventions, they remain firm on the position that sterilization is not religiously permissible as it permanently limits childbearing capacity. 
"We want to use FP, give it a chance, but due to the qabaili [tribal] system, we cannot do it. There is opposition from the family and we get taunted that you are a slave of the woman."

- Male, rural area, Pishin

"A lot of people think of it as a standard; mostly qabaili people don't have spacing due to feuds. Our elders and maulvi [religious clerics] say that children are a very big blessing."

- Male, rural area, Sibi

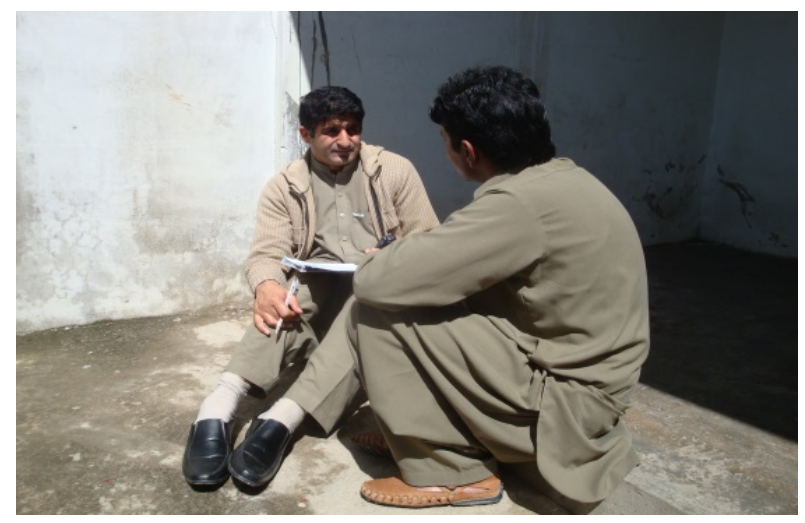

\section{Rural Men Find it Difficult to Reach Health Facilities}

Public health facilities are few and far between, which makes each visit a major undertaking. Rural men and women often have to travel large distances to reach FP services. For the most part, they do not own their own means of transportation, while availability of affordable transportation services is low. Difficult terrain can exacerbate this problem, as in extensive parts of Balochistan and KP (Kamran et al. 2015). In addition, female mobility is often limited in rural areas, which means somebody—usually their husbandmust accompany them on the long trip to the nearest health facility. This entails a considerable loss of productive time for both. Couples who do not have enough to feed their children, or who must work long hours to make their daily living often cannot afford to make the trip.

"I told you about the financial conditions that on one side there is poverty and on the other band the hospital is 10 or 12 kilometers away, so for this reason, using these methods is out of our range."

- Male, rural area, Mardan

"In the village, there are burdles in everything. Since there is no work, we have problems of money, feeding our children...we do not have proper roads, and transport is also not available. A poor person cannot even go to bealth facilities. Those who have a car can go; where can a poor person go?"

- Male, rural area, Sibi

High travel costs comprise a major hurdle. Longer distances and low availability of transportation services translate into higher travel costs. Since men do not prefer their wives to travel alone, they accompany them on each visit, doubling the travel fare. Sometimes, they have to hire costly private vehicles when other transportation is not available. Moreover, at times, couples reach facilities only find that they have to come back later because service providers or contraceptives are unavailable. This further increases the travel costs of care and discourages future visits. In these circumstances, men with very limited financial resources are unable to act on their intention to use FP. This is particularly a problem in unserved and poor areas (Kamran et al. 2015).

\footnotetext{
"A person who wants to use a method worth 6 rupees has to spend 65 rupees on transport. When facilities are available locally, it saves time as well as travel costs."

- Male, rural area, Rahim Yar Khan

"The main hospital is very far from bere and often at times the transport is not available.
}

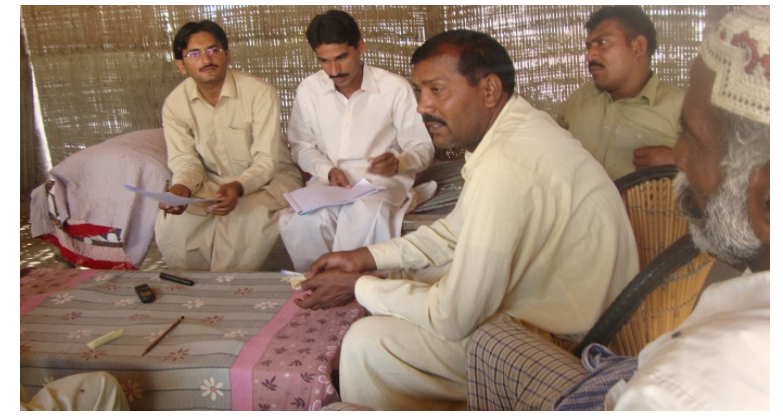


When people get there with difficulty then the message is conveyed to us that the doctor cannot come today and you people should come later. Then, sometimes, we do make these repeat visits but when we get to see the doctor at last, the contraceptives are not available. After seeing all these difficulties, a person does not want to go there again."

- Male, rural area, Mardan

\section{Public Health Facilities Lack an Adequate Number of Service Providers and their Availability is Often Limited}

Poor access to female service providers is a common problem in rural areas. The cultural environment of Pakistan does not allow men to take their wives to male service providers for FP care. This issue is especially pronounced in Balochistan, where the restrictions of gender segregation are more entrenched, and where the availability of female providers is extremely low. Although female service providers are more available in Punjab, KP, and Sindh, there is frequent absenteeism, tardiness, and a tendency to arrive late and leave early. Combined with already short working hours and only morning hours of many public health facilities, there is a good chance that when men bring their wives to health facilities they will not be able to consult a qualified provider (Kamran et al. 2015). After experiencing such a disappointment, men are reluctant to risk time and resources for another visit.

"In government bospitals, there are no staff, no lady doctors and no medicines. In this situation, what is the benefit of going there for treatment? Neither doctors are present nor are medicines available. Even injections for family planning are not available there."

- Male, rural area, Khairpur

LHWs can only partially fulfill the need for female service providers. Many rural communities are served by LHWs, but the LHW program is directed at women, not men. These community-based workers are trained to provide only basic services. They dispense condoms, pills, and subsequent doses of injectables, but are not qualified to provide more specialized counseling, insert and remove IUCDs, administer the first injection, or help clients manage side effects. Therefore, people still have to visit health facilities for clinical methods and for management of side effects (Kamran et al. 2015). The effectiveness of LHWs is further curtailed by frequent breaks in the supply of contraceptives to them.

"Here, there is no such service available. We have to take women to Sibi [for clinical methods]. If there is any such service in Sibi, then it is okay; otherwise, we bave to take them to Quetta. And the issue is that we don't have services in our village."

- Male, rural area, Sibi

Moreover, the LHW program has yet to expand to all rural areas and the neediest communities, and has particularly poor coverage in Balochistan where local educated women are hard to recruit.

Male FP service providers are in short supply. To a great extent, the existing infrastructure for FP service provision in Pakistan is geared to meet the needs of women through women providers. At public and private hospitals, FP services are closely linked with gynecology and obstetrics services. In the field, it is lady health workers, and not male health workers, who dispense FP methods, even condoms.

When a man arrives at a public or private health facility, he finds no point of contact to cater to his FP needs. Cultural norms make it highly inappropriate for him to approach a female provider for advice. On the other 
hand, by and large, male doctors eschew involvement in FP, considering it a female as well as a lower-skill domain (Haque et al. 2012).

Men seeking to make informed FP choices are frustrated by the difficulty of finding someone to talk to who will listen to their questions and concerns, and provide them the details, products and services they need. This issue also severely limits their capacity to support their wives' adoption and continuation of FP, especially when language barriers complicate the interaction between their wives and the service provider. Women from remote communities, particularly in Balochistan, sometimes speak only the local language or dialect, which may be hard to understand for service providers, who are usually not from the local area. In these situations, husbands, who are often capable of translating, cannot help because they are barred from the interaction (Kamran et al. 2015).

\section{Public FP Service Providers Do Not Inspire Men's Trust}

Service providers at public health facilities are often very rude to patients, which can discourage potential FP clients. Women seeking care on sensitive FP matters may find themselves confronted with a bewildering lack of sympathy and courtesy, disparaging and dismissive attitudes, and lack of privacy. This problem is commonly faced by women to varying degrees in all provinces.

Many public sector service providers demand that their clients visit them at their evening private practices. At these clinics, their behavior is markedly different: their attitude is positive and polite, and they exercise greater care in understanding and responding to their clients' questions and concerns (Kamran et al. 2015). However, poor men cannot afford the fees for these services.
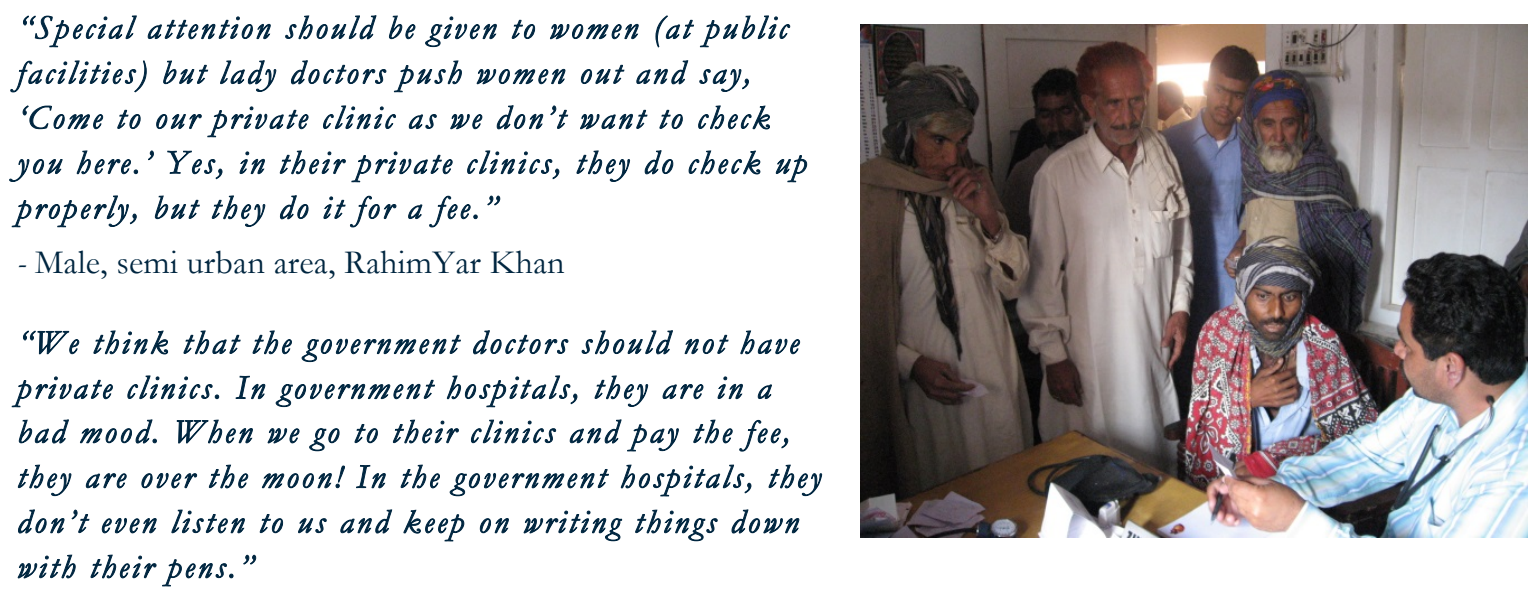

- Male, semi urban area, Rahim Yar Khan

Men perceive the skills of service providers, including LHWs, to be inadequate, especially when they or their wives experience perceived or actual contraceptive side effects. Men feel that providers lack the skills required to manage contraceptive side effects and provide appropriate counseling (Kamran et al. 2015). This lack of confidence not only acts as a barrier to FP adoption but is also one of the most important obstacles in the continuation of FP practice by men and women.

"If a woman is using an IUCD, and she experiences excessive bleeding, this LHW does not bave much information (to belp her). They don't have information regarding such illnesses."

- Male, urban area, UmerKot 
Among users of contraception, actual experience of side effects-such as heavy or irregular bleeding among women-may lead men to encourage their wives to temporarily or permanently discontinue a method, especially injectables and IUCDs. The discontinuation is driven not only by women's physical suffering, but also by the resulting deterioration in their quality of life, compromised ability to work, extra expenditure on healthcare, and damage to marital relationships (Kamran et al. 2015). In addition, the actual and perceived inability of service providers to provide sufficient information and treatment to manage side effects is a major factor that leads men to conclude that the method should be discontinued.

\section{Men Consider Public Facilities/Providers to be Unreliable Sources of Contraceptives}

The non-availability of contraceptive stocks at public health facilities is a major issue reported by men from all provinces, especially Balochistan, Punjab, and Sindh. Usually, injectables, IUCDs and condoms remain out of stock at public facilities and providers ask couples to purchase them from the market (Kamran et al. 2015). The likely non-availability of contraceptive products acts as a further disincentive for men to visit health facilities for FP care.

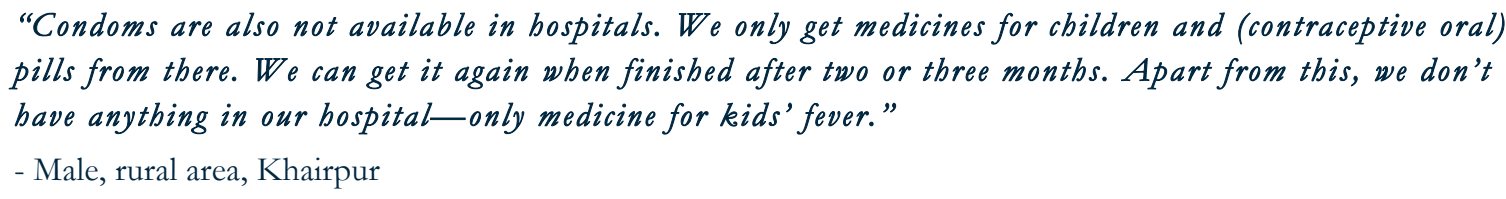

Men suspect that the quality of contraceptives provided at public facilities is poor. There is a common misperception among men that the condoms provided by public health providers are of poor quality and therefore rupture easily, causing allergic reactions among men, and hurting their wives (Kamran et al. 2015).

\section{Private FP Services are Unaffordable for Many}

Across all provinces, men prefer to visit private rather than public healthcare facilities for FP services because they perceive private providers to offer greater method availability and better quality of care. In their view, private providers interact more politely with clients, provide proper information about the FP method, and conduct thorough check-ups, which is not the case at most public facilities (Kamran et al. 2015).

However, men who are unable to afford private services have no choice but to avail public facilities, despite the likely poor quality of care, or to live with unmet need for FP.

"The private providers do check-ups properly, they satisfy the clients, and when you go in the government, there they don't do proper check-ups. They only tell us what's wrong, write down the prescription, and then ask us to leave."

- Male, semi urban area, UmerKot

\section{Men's Difficulties in Accessing and Using Condoms}

In general, almost all men know about condoms and the method is preferred by most. Even so, several factors hinder their use of this method:

Embarrassment in buying condoms is commonly mentioned by men from Balochistan, KP, and Punjab (Kamran et al. 2015). Open discussion of reproductive health issues is not a norm in Pakistani society, and a pervasive culture of haya (modest shyness) makes it difficult for many men to negotiate the otherwise simple task of purchasing condoms from the local store. In some cases, men's inhibitions on this 
score are worsened by the insensitive conduct of shop attendants, who pass inappropriate remarks during the transaction.

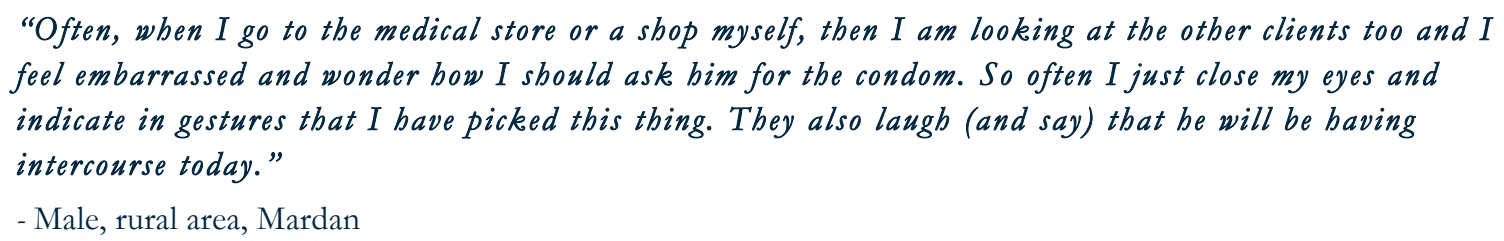

The LHW program has relieved men of the need to access condoms directly, but only in areas served by the program and as long as LHWs' supplies last. When the LHWs' stocks run out-as they frequently do-men in LHW-served areas are in the same boat as their peers in non-served areas.

Apprehension about possible condom side effects also holds men back. Men sometimes perceive that the lubricants on condoms cause wounding or trigger allergic reactions or infections. Fear of rupture of condoms also makes men reluctant to use them. Another problem mentioned is reduced satisfaction. These issues exist in all provinces but are more commonly reported from Balochistan and KP (Kamran et al. 2015).
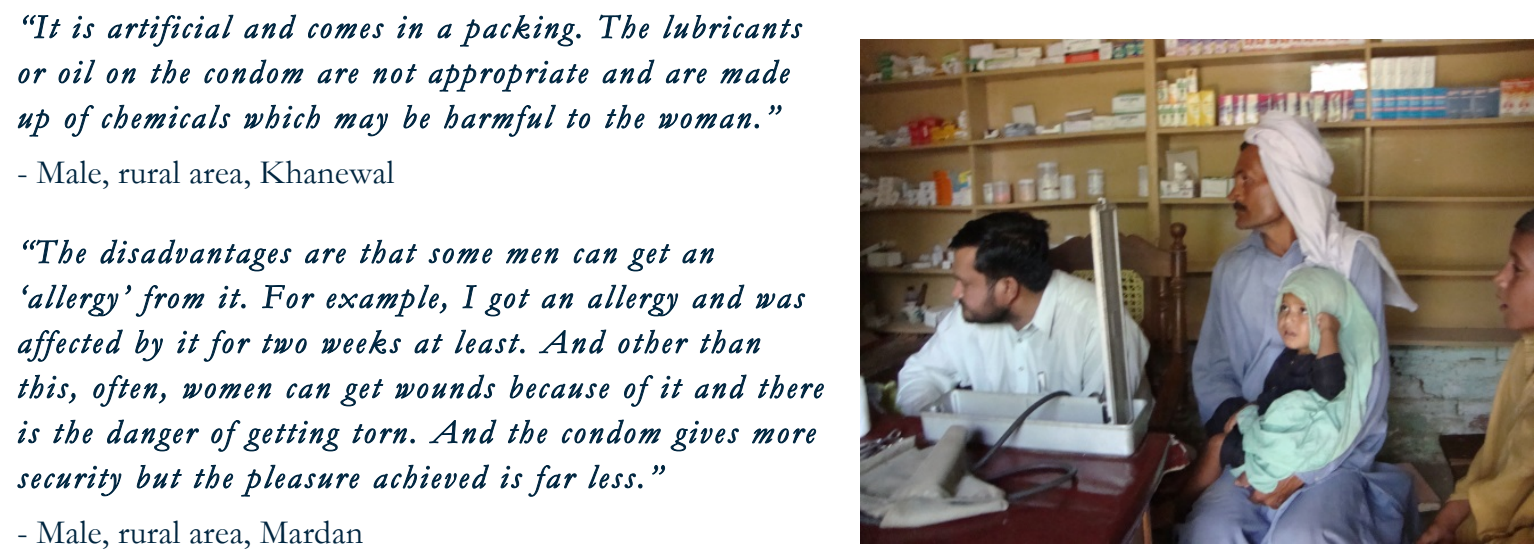

Men worry about the poor quality of condoms. They commonly believe the products supplied by LHWs and available for free at public health facilities are substandard, i.e., more likely to rupture, cause side effects, and reduce satisfaction. This issue is voiced particularly by men from Punjab and KP. In their view, the products in the market, though high priced, are safer and interfere less with satisfaction (Kamran et al. 2015).

"The products available at facilities in the government sector are of very bad quality. Often, we are given those things [condoms] but there is a lot of fraud involved; they are not worth using. I told you before about the harmful side effects-that the condom often tears and it does not give the natural pleasure."

- Male, semi-urban area, Mardan

"They are not of good quality. The ones which are of good quality are expensive; they cost around 50 rupees per condom minimum, and the cheap one is not of good quality and, aside from this, it does not give the natural pleasure."

- Male, rural area, Mardan

Stock outs and expiration of condoms are a frequent complaint of men, especially in KP. Again, it is perceived that these issues are more common about condoms from public health facilities (Kamran et al. 2015). 


\section{Imbalance in Use of Withdrawal}

More urban men prefer to use withdrawal while rural men know little about it. According to PDHS 2012-13, withdrawal is the most popular traditional method and it is being used by 9 percent of men. This is almost double the usage that was reported in PDHS 2006-07. Across almost all provinces, the increase in use of withdrawal is more commonly found among urban and educated men than rural men. On the other hand, unexpectedly, rural men from unserved areas have very limited knowledge about withdrawal. In these areas, even men who do know about the method prefer not to use it because they feel it is hard to follow and therefore has a high chance of failure (Kamran et al. 2015).

"They don't trust the traditional method because they can't have control over themselves. They don't have trust over themselves that will they be able to use this (withdrawal) method; that's the reason they don't give importance to it."

- Male, semi urban area, Khairpur

Men in both urban and rural areas require information and counseling regarding the appropriate use of withdrawal, the risks of failure, and the advisability of pairing it with the rhythm method. Men need to be advised that withdrawal is too unreliable to be their primary option, but is a good fallback method for when other FP choices are not available, as may be the case in non-served areas.

\section{The Undiscussed Option of Vasectomy}

Male sterilization is a less known and rarely used method in Pakistan. According to PDHS 2012-13, 47 percent of currently married men know about vasectomy. However, only 0.3 percent have undergone the procedure and it is rarely discussed as an option.

Men fear that sterilization will result in impotency. The large gap between knowledge and use of the method implies that Pakistani men have strong reservations about vasectomy. A major reason for this is the misapprehension that the procedure will make them impotent (Kamran et al. 2015).

"With the method of vasectomy, men have fear of losing their manbood forever."

- Male, rural area, Mansehra

"With the operation, the sperms of the man get destroyed. They cut down the tubes of semen. With this the sperms don't go any further. My friend had it done and be said that they either cut the tube or tie it up and put medicine on it."

- Male, rural area, Rahim Yar Khan

Services for conducting male sterilization are largely unavailable. The highly limited availability of the specialized services required to conduct male sterilization could also be a major reason for the low use of this method. Given the huge difference in the use of male and female sterilization to limit childbearing, there is a need to promote vasectomies to contribute in raising the CPR. Men's apprehension about vasectomies will need to be addressed through a comprehensive set of interventions ranging from counseling to service provision. It will have to be ensured that at least one well-equipped and adequately staffed facility is available to conduct safe vasectomies in each district. 


\section{SUPPORTING MEN: THE POTENTIAL OF MALE PROVIDERS IN THE PRIVATE SECTOR}

The preceding section indicates that men need help to overcome the problems that hinder their adoption and continued use of contraception. Their growing involvement in FP and the increasing share of male methods in overall contraceptive use must be supported with new, responsive strategies. Specifically, men need easy access to male service providers who can meet their needs while offering affordable and better quality of care than that available in the public health sector.

Public sector FP services are inadequate for meeting men's FP needs. Family planning forms an important component of public health services in Pakistan and the latest draft population policies of the provincial Population Welfare Departments reflect an incipient awareness that men's specific FP requirements also need to be addressed. However, the coverage and quality of public FP services are greatly constrained by lack of resources and problems of governance and management. Further, there are no particular interaction opportunities between men with FP need and the service delivery system in the public sector. The public sector mainly relies on female service providers for FP services, and male providers are usually untrained in FP. As an immediate measure, exisiting male technical staff, such as male health technicians (MHTs), should be assigned the responsibility to provide family planning services to male clients.

The private sector's potential to contribute to FP needs to be explored in view of the urgent need for a rapid response to unmet need in general and bottlenecks in men's practice of FP in particular, as well as the considerably greater presence of private providers.

The private sector offers wider coverage and a much higher number of male providers. Currently, private sector facilities greatly outnumber public healthcare facilities in both urban and rural areas. A study of 34 districts found that slightly over half (52 percent) of all kinds of healthcare providers are working in the private sector, and significantly more male providers are working in the private health sector than female providers. However, the proportion of private providers varies across provinces, being lowest in Balochistan and highest in Punjab (Haque et al. 2012).

Only a small proportion of the private health sector is engaged in social marketing of FP services, primarily in urban areas. Internationally, many strategies have been developed and implemented to enhance the private sector's contribution to FP, such as social marketing, provider training, and demand-side financing. In Pakistan, Green Star Marketing (GSM) is the leading private organization in the provision of birth spacing information and services, including advertising campaigns, sale of contraceptives at subsidized rates, and training of doctors, paramedics, and chemists. However, Haque et al. (2012) found only about 4 percent of private providers are affiliated with GSM and its activities are mainly restricted to urban and periurban areas.

The private sector, outside of subsidized social marketing efforts, has only limited involvement in the provision of FP services. Only 38 percent of private facilities in 34 districts of Pakistan are offering one or more FP services compared to 66 percent of public facilities. The reasons for this are not immediately clear but possible explanations include a lack of demand, lack of training of private sector providers, inadequate profit potential, and a lack of readily available contraceptive supplies (Haque et al. 2012).

Dispensers provide FP services to both men and women and outnumber other female as well as male providers. A study of 34 districts found that while female general practioners (GPs) and Lady Health 
Visitors (LHVs) are the main source of FP services, male GPs and dispensers are also providing FP services to both men and women. Data indicate that dispensers outnumber female GPs and LHVs by a ratio of 7:1 and male GPs by a ratio of 2:1 (Haque et al. 2012).

Dispensers ${ }^{3}$ are more numerous and concentrated in rural areas where other service providers are less available. There are nearly three times as many dispensers than male GPs 4 in rural areas. The data indicates that they are providing more FP services even to female clients than LHVs and male and female doctors in rural areas (Haque et al. 2012).

Dispensers' role in FP service provision generally equals or exceeds that of male GPs. Currently, 49 percent of male GPs and 54 percent of dispensers are providing FP services compared to 92 percent of female GPs and 92 percent of LHVs. Figures 6 and 7 show that dispensers are playing a larger role than male GPs in FP service provision in KP and Balochistan, and they also have a slightly larger role in the provision of injectable contraceptives (Haque et al. 2012).

\section{FIGURE 6}

Proportion of two cadres of male providers providing FP services, by province

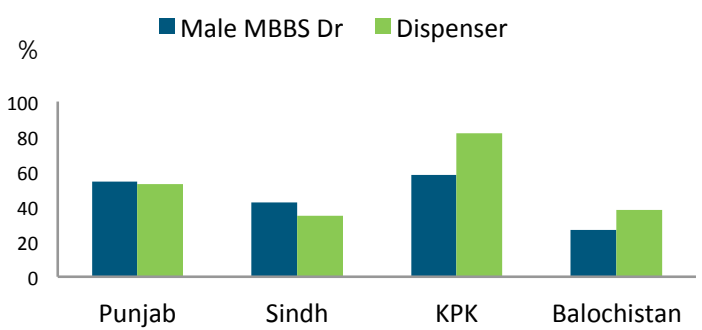

\section{FIGURE 7}

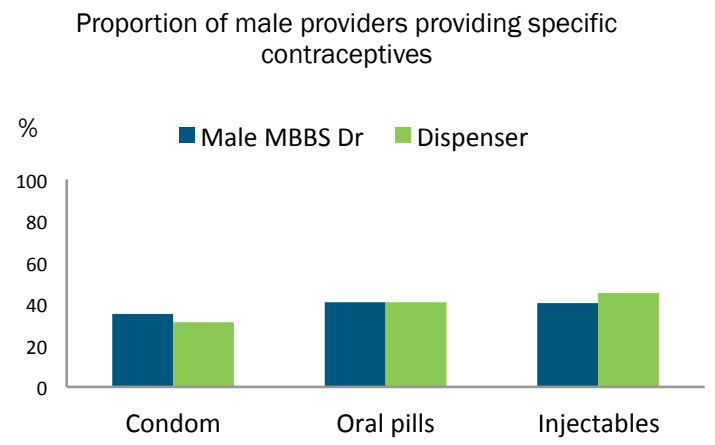

Source: Role of private sector in delivering birth spacing services in FALAH districts 2011-12

Male providers have more gaps in their knowledge of contraceptive technology and side effect management than female providers. All classes of providers show limitations in their understanding and perspectives on contraceptive technology, and report giving inadequate information and counsel to clients, especially regarding side effects and their management. However, this is especially true of male providers. However, despite being the least trained cadre, dispensers have better knowledge about specific details of female FP methods than male GPs. This indicates strong interest in and potential for formal FP service provision (Haque et al. 2012).

It is generally believed that the lack of proper counselling of clients to tolerate side effects of contraceptive methods contributes substantially to high rates of discontinuation and the general fear of modern methods in Pakistan. Therefore, it is essential that this weakness be addressed.

Male providers have less training in FP than female providers, but they are willing to fill the gap. Nearly 90 percent of dispensers and 58 percent of male GPs have no training in FP, compared to less than 30 percent of female GPs and LHVs. The majority of male providers are interested in receiving FP training. A

${ }^{3}$ Dispensers are male paramedics with 'dispenser' certification by the relevant Provincial Medical Faculty, who serve in both the public and private health sectors. They mainly manage stores, pharmacies, equipment, buildings, and front desks, maintain records and dispense medicines on doctors' prescriptions. However, in rural unserved areas, they mainly run private clinics as health service providers.

${ }^{4}$ MBBS doctors 
third of male doctors and nearly 45 percent of dispensers feel that this would enhance their knowledge about birth spacing methods. Dispensers are willing to spend 7 days on such training while MBBS doctors are willing to dedicate 5-6 days (Haque et al. 2012).

\section{Male GPs are less interested in FP service provision than dispensers but hold potential in urban}

areas. Male GPs do not appear to be strongly interested in FP service provision. This could be due in part to lack of potential business gain. Nevertheless, the relatively modest scale of activities of many physicians, coupled by the interest expressed by some to expand their work, suggests that there is room to test efforts to involve them more fully. Such undertakings are most likely to succeed in urban areas, where there is a greater concentration of GPs, better potential for partnerships with social marketing concerns, and higher demand among men for more qualified providers (Haque et al. 2012).

Dispensers are driven and offer strong potential to meet men's FP needs in rural areas. There are nearly three times as many dispensers as male GPs in rural areas. Despite their limited training and knowledge, they are playing a larger role in FP service provision, particularly in the provision of condoms, oral contraceptive pills, and injectables than male doctors. They also demonstrate better knowledge of FP methods than male doctors, as well as a strong willingness to be trained and more actively involved in FP service provision. A vital advantage is that they are already catering to women's FP needs, and this is reflected in their unexpectedly better knowledge of female contraceptive methods.

Through appropriate training, a regular supply of contraceptives, and greater integration in the FP programming framework, it is possible to galvanize the vast network of dispensers to address the urgent FP needs of both men and women in rural areas. 


\section{Recommendations}

The new positive outlook of men on FP represents a great opportunity to boost contraceptive prevalence and thereby reduce the pace and burden of population growth, improve maternal and child health indicators, and accelerate economic development. The majority of men are ready to participate and share responsibility in the practice of FP. However, unless policymakers respond quickly and effectively, the current high motivation and interest of men could be replaced by disillusionment, and they could join the ranks of thousands of "ever users" who were compelled to discontinue FP practices due to chronic issues of limited access, unresolved side effects, poor quality of products and care, and a callous lack of support from healthcare providers.

The following measures are recommended to meet men's FP needs:

- Mainstream men in FP policy and management. FP has a woman's face in Pakistan. The exclusive focus on serving women's needs through female providers severely limits men's ability to access FP services and blinds the health system to their unique needs. At all levels, from national and provincial policies to management policies and plans at public and private facilities, men's needs for FP-related information, counseling, products and services need to be acknowledged and suitable arrangements made.

- Adopt a birth spacing paradigm. For male users as well as a significant proportion of service providers, FP is vastly more acceptable as a method of birth spacing than fertility limitation. This is because spacing births is seen to be more consistent with Islamic principles than the idea of stopping births. Operating in a paradigm that is harmonious with the faith of the masses will minimize social pressure on users and providers alike.

- Develop cadres of male FP service providers. To help men overcome the challenges they are experiencing in practicing FP, it is essential that they be provided access to male service providers. This need can be filled at public as well as private facilities by trained male GPs in urban areas and trained dispensers in rural areas. Moreover, just as LHWs deliver FP information, counseling and contraceptives to women at their doorsteps, a cadre of male health workers (MHWs) should be developed for individual as well as group counseling of men, provision of condoms, and referral to appropriate health facilities where needed. MHWs are especially needed in Balochistan and KP where difficult terrain makes it harder for remote communities to access facilities.

- Incentivize FP service provision for private providers. Options should be explored by the Population Welfare and Health Departments, perhaps with the help of social marketing concerns such as GSM, to engage private service providers and keep them motivated to provide FP services, particularly to men.

- Train all FP service providers, especially in side effect management. To ensure that men have adequate support in use of FP methods, especially in the management of side effects of both male and female methods, it is essential that all, especially male, FP service providers be fully trained in the various male and female methods of contraception. Moreover, they should be trained to follow the client-centered approach in service provision so that men remain motivated and do not feel offended or neglected during consultations. The Population Welfare Department, public hospitals, and GSM resources should be equipped and mobilized to conduct such trainings.

- Inform men and address their concerns. All possible channels, including individual interaction with male service providers (e.g., MHWs, dispensers, and male doctors), men's meetings at community levels (conducted by MHWs), and radio and TV should be employed to inform, educate, and communicate with men regarding the options of contraception, their reliability and usage, 
expected side effects and how they can be managed, and to refer them to suitable public and private sector facilities. To increase use of vasectomy, more information and counseling should be provided regarding this method and where it can be obtained. Apprehension about perceived side effects of condoms should especially be addressed and more information provided to men about their correct usage.

- Understand and respond to the reasons underlying urban men's increasing use of withdrawal. Since withdrawal is a less reliable method than modern contraceptives, its increasing use among urban, educated men — who generally have easier access to more reliable alternatives-is worrying. This trend must be watched and understood so that responsive interventions can be mounted. It is possible that the preference for withdrawal is due to perceived or actual side effects of modern contraceptive methods (Kamran et al. 2015), but the issue should be studied for a complete and accurate understanding.

- Ensure easy and uninterrupted access to condoms. Special attention should be paid to the supply of condoms to communities through different channels, including LHWs and public facilities as well as private sector channels. A systematic supply system should be created to provide male providers with contraceptives free of charge or at subsidized prices. In addition to drugstores, owners of other frequently visited facilities, such as tea stalls, paan shops, barber stalls, and vegetable shops, should be encouraged to keep stocks of condoms that can be discreetly purchased by men. 


\section{References}

Ali, S. R. 1999. Men and Reproductive Health in Punjab: Perspectives from 37 Discussion Groups. Research Report No. 10. Population Council Islamabad.

Arif, S. and Kamran, I. 2007.Exploring the choices of contraception and abortion among married couples in Tret, rural Punjab, Pakistan. Population Council, Islamabad.

Avan, B. I. and Akhund, S. 2006. Role of Family Type in the Idealization of a Larger Number of Children by Husbands in Pakistan. Journal of biosocial science 38 (2): 203-220.

Casterline, J. B., Sathar, Z. A. and Haque, M. U. 2001. Obstacles to Contraceptive Use in Pakistan: A Study in Punjab. Studies in Family Planning 32 (2): 95-110.

Haque, M. U., Miller, P. and Kamran, I. 2012. Role of Private Sector in Delivering Birth Spacing Services in FALAH Districts. Population Council, Islamabad.

Kamran, I., Khan, M. and Tasneem, Z. 2013. Involving Men in Reproductive and Fertility Issues: Insights from Punjab. Population Council, Islamabad.

Kamran, I., Tasneem, Z., Parveen, T. and Zaidi, Y. Z. 2015. Investigating low modern contraceptive use in Pakistan. Population Council, Islamabad.

Kiani, F. K. 2003. Motivation and Involvement of Men in Family Planning in Pakistan. The Pakistan Development Review; 42 (3): 197-217.

Mahmood, N. and Ringheim, K. 1996. Factors Affecting Contraceptive Use in Pakistan. The Pakistan Development Review 35(1): 1-22.

Mahmood, N. and Ringheim, K. 1997. Knowledge, Approval and Communication about Family Planning as Correlates of Desired Fertility among Spouses in Pakistan. International Family Planning Perspectives 23(3): 122-145.

National Institute of Population Studies (NIPS) and IRD/Macro International Inc. 1992. Pakistan Demographic and Health Survey 1990-91. Columbia, Maryland USA: NIPS and IRD/Macro International Inc.

National Institute of Population Studies (NIPS) and Macro International Inc. 2008. Pakistan Demographic and Health Survey 2006-07. Islamabad, Pakistan: National Institute of Population Studies and Macro International Inc.

National Institute of Population Studies. 2013. Pakistan Demographic and health Survey 2012-13. Islamabad. Pakistan and Calverton, Maryland, USA: NIPS and ICF International.

Population Council and Ministry of Population Welfare. 1998. A Qualitataive Investigation into the Use of Withdrawal. Research Report No. 6. Population Council Islamabad.

Tuloro, T., Deressa, W., Ali, A. and Davey, G. 2006. The Role of Men in Contraceptive Use and Fertility Preference in Hossana Town, Southern Ethiopia. Ethiopian Journal of Health Development 20 (3): 152-159. 


\section{Appendix 1: Principal Data Sources}

This paper is based primarily on findings from the following studies:

- Investigating Low Modern Contraceptive Use in Pakistan (Kamran et al. 2015). This national level qualitative study was conducted by the Population Council in 2014 as part of an extensive research project to determine why use of modern contraceptives in the country remains so low despite large unmet need. The policy paper utilizes the portion of the study that explored men's FP perceptions and behaviors, including provincial variations, based on 33 in-depth interviews and 32 focus group discussions with men from urban and rural communities in areas served by the LHW program as well as areas beyond its reach (Non-LHW rural area).

- Involving Men in Reproductive and Fertility Issues: Insights from Punjab (Kamran et al. 2013). This qualitative study was conducted by the Population Council in four districts of Punjab to explore fertility intentions and practices and the intervening decision-making processes as well as community perceptions of male-focused interventions and men's own suggestions for future FP interventions. It informs the discussion of men's current perception of FP.

- Pakistan Demographic and Health Survey 2012-13 (National Institute of Population Studies [NIPS] and Measure DHS 2013). The latest PDHS 2012-13 has been used to analyze change in men's fertility behavior and preferences over time. The survey interviewed 3134 ever-married men age 15-49 years regarding several health issues; this paper utilizes data related to men's knowledge and use of family planning methods and their fertility preferences.

- Exploring the Choices of Contraception and Abortion among Married Couples in Tret, Rural Punjab, Pakistan (Arif et al. 2007). This small-scale qualitative study by the Population Council explored choices of contraception and abortion among couples living in a village in Punjab in 2006. Data from the study has been used to determine trends (through a comparison of past and recent findings) in perception of FP, spousal communication and its role in FP uptake decisions, and the role of the husband in decision-making.

- Role of Private Sector in Delivering Birth Spacing Services in FALAH Districts (Haque et al. 2012). Under this national level study, conducted under the Family Advancement for Life and Health (FALAH) project in 2011-12, nearly 500 male doctors and dispensers at private health facilities were interviewed regarding their current and planned role in FP service provision, and related knowledge and training. Findings of the study have been used to explore the readiness of the private health sector to meet men's FP needs. 
The Evidence Project

Population Council

4301 Connecticut Avenue, NW, Suite 280

Washington, DC 20008 USA

tel +12022379400

evidenceproject.popcouncil.org 